\title{
Effect of a Community-Level HIV Prevention Intervention on Psychosocial Determinants of HIV Risk Behaviors among Young Black Men Who Have Sex with Men (YBMSM)
}

\author{
Agatha N. Eke ${ }^{1}$. Wayne D. Johnson ${ }^{1}$ - Ann O'Leary ${ }^{1}$ - Gregory M. Rebchook ${ }^{2}$. David M. Huebner ${ }^{3}$. John L. Peterson ${ }^{4}$. \\ Susan M. Kegeles ${ }^{2}$
}

Published online: 23 April 2019

(c) This is a U.S. Government work and not under copyright protection in the US; foreign copyright protection may apply 2019

\begin{abstract}
In contrast to intervention studies that assess psychosocial factors only as mediators or moderators of HIV risk, the present study assessed the effects of an Mpowerment-based community-level intervention on psychosocial determinants (e.g., depressive symptoms, sexual stigma) of HIV risk behavior among young black MSM. Approximately 330 respondents were surveyed annually for 4 years in each of two sites. General linear models examined change across time between the intervention and comparison communities, and participation effects in the intervention site. Social diffusion (spreading information within networks) of safer sex messages $(p<0.01)$ and comfort with being gay $(p<0.05)$ increased with time in intervention versus control. Cross-sectionally, intervention participants responded more favorably $(p<0.05)$ on social diffusion and depressive symptoms, but less favorably $(p<0.01)$ on sex in difficult situations and attitudes toward condom use. Findings suggest a need to address broader health issues of MSM as well as sexual risk.
\end{abstract}

Keywords Psychosocial · Syndemic · HIV · MSM · African American · Young black MSM

\section{Resumen}

En contraste con estudios de intervención que sólo evalúan los factores psicosociales como mediadores o moderadores de riesgo al VIH, el presente estudio determinó los efectos de una intervención a nivel comunitario llamada Mpowerment [empoderamiento] sobre los determinantes psicosociales (Ej., síntomas depresivos, estigma sexual) que afectan el riesgo al VIH en jóvenes HSH Afroamericanos. Alrededor de 330 participantes fueron encuestados anualmente por cuatro años en cada uno de los dos lugares del estudio. Modelos estadísticos lineares examinaron cambios a lo largo del tiempo entre las comunidades de intervención y de control, y los efectos en los participantes que eran parte de la intervención. La difusión social (difusión de información dentro de redes) de mensajes sobre sexo seguro $(\mathrm{p}<0.01)$ y el sentirse cómodo siendo gay $(\mathrm{p}<0.05)$ aumentaron con el tiempo en el grupo de intervención versus el grupo control. En forma transversal, los participantes que eran parte de la intervención respondieron más favorablemente $(\mathrm{p}<0.05)$ a la difusión social y los síntomas depresivos y menos favorablemente $(\mathrm{p}<0.01)$ al sexo en situaciones difíciles y las actitudes hacia el uso del condón. Los hallazgos sugieren la necesidad de abordar el riesgo sexual y los problemas de salud de HSH desde una perspectiva más amplia.

Palabras claves Psicosocial $\cdot$ Sindemia $\cdot$ Sindémico $\cdot$ VIH $\cdot$ HSH $\cdot$ Afroamericano $\cdot$ Joven HSH negro/Afroamericano

\section{Introduction}

Agatha N. Eke

aee2@cdc.gov

Extended author information available on the last page of the article
There has been significant progress in HIV prevention with the onset of biomedical strategies, including early detection, treatment and viral load suppression for individuals who are HIV-positive, and pre-exposure prophylaxis (PrEP) for high-risk HIV-negative individuals [1-3], coupled with proven HIV behavioral risk-reduction strategies [4]. 
However, alarming disparities persist among certain risk populations, including young black men who have sex with men (YBMSM), who continue to experience disproportionate new infections [5], as well as disparities across the HIV care continuum (greater difficulty accessing, engaging and remaining in care) [6-8]. Social environmental contexts such as policy and cultural factors result in stigmatization, homophobia and discrimination against people of same-sex attraction and with HIV [9, 10], thus fostering psychosocial challenges long determined to play a significant role in HIV risk among YBMSM [11, 12].

Psychosocial problems may be a combined result of individual psychological dispositions and efforts to cope with the context of challenging social environments. Some coping mechanisms can negatively impact mental health and HIV risk-reduction outcomes [13-17]. Psychosocial problems tend to correlate, together creating a syndemic of problems that increases YBMSM vulnerability to HIV and AIDS [17-21]. Psychosocial problems often can manifest as depression and anxiety, internalized oppression (such as internalized racism and homophobia), low sense of self and self-agency, and social isolation that have been shown to co-occur with risk factors for HIV and AIDS [20-24]. Compared to the general population, sexual minorities including YBMSM are at greater risk for mental health problems, including anxiety and depression [25]. YBMSM, like many sexual minority groups, experience and grapple with complex social, psychological and cultural obstacles $[19,26]$. They also experience overlapping alienation based on race [27], giving them a multiple minority status [26], with disparities in unemployment, homelessness, incarceration history, family instability, breakup of relationships, lack of access to health care, poverty, and drug-related violence [28-30]. Experiences of homophobia, family rejection and social isolation by YBMSM can lead to expectations of rejection [31], non-disclosure of sexual orientation, and internalized stigma and homophobia [32]. These may limit their opportunity and ability to benefit fully from HIV risk reduction and treatment and care strategies including linkage and retention in care, and use of antiretroviral therapy (ART) for HIV positive individuals [6, 19, 32-34], as well as use of PrEP for HIV negatives $[6,8,35]$. Racism, homophobia, and depression have been shown to have indirect effects on the occurrence of unprotected anal intercourse (UAI) through difficult sexual situations [36].

Despite the relevance of psychosocial factors in framing the broader concerns of YBMSM [20, 21], and their documented role in driving HIV rates especially among this population, they often are not the primary focus of intervention studies and are not reported as intermediate outcomes of interventions. Instead, they are studied only peripherally and reported as predictors, mediators, or moderators of intervention effects on behavioral and treatment outcomes (condom use, multiple sex partners, HIV testing, linkage, engagement in care) $[10,19,37,38]$. While interventions that change individual behavioral risks have contributed significantly to stemming the HIV epidemic [4, 39], surveillance reports have consistently shown continued disproportionate burden of the disease among YBMSM [5], thus bringing to focus the need to examine and intervene on determinants beyond individual risk behaviors. As the field marches towards achieving zero infections in a very near future it has become necessary for interventions to focus beyond behavioral risks, and target the broader psychosocial problems that drive and/ or co-occur with high rates of HIV among YBMSM. In this study, a set of analyses was carried out using data from a community-level intervention with YBMSM to investigate psychosocial experiences, not as mediators or moderators of intervention effects, but the extent to which they were improved or modified by the intervention.

\section{Study Objectives}

The original Mpowerment intervention [40] was designed to promote safer sex among young MSM through social diffusion. The current adaptation also promotes HIV testing. In this analysis we assessed the effectiveness of the adapted Mpowerment-based community-level intervention in modifying potential mediating variables that may be causally related to HIV risk-reduction behaviors (safer sex and knowledge of serostatus), as well as any influence on psychosocial circumstances and experiences that are indicators of positive mental health and well-being in their own right. Specifically we examined effects on traditional cognitive variables including self-efficacy, condom attitudes and social norms that several behavioral theories [41, 42] have suggested may predict, influence, or mediate behavior change.

In addition, we examined the effect of the intervention on comfort with being gay, experiences of depressive symptoms, social diffusion of safer sex messages and social support. The expectation was that positive psychosocial variables including comfort with being gay, social diffusion of safer sex messages, self-efficacy, safer sex norms and social support should increase, while negative psychosocial variables including depressive symptoms and difficult sexual situations and relationships should decrease (Fig. 1). We investigated three additional experiential and attitudinal variables (perceptions of racism, perceptions of external homophobia, and treatment optimism) for which there was no a priori directional hypothesis but which could be influenced by intervention activities and in turn could be associated with the desired behavioral outcomes. These variables are critical given their potential influence on desired HIV behavioral outcomes among YBMSM. Improvement in psychosocial factors have the potential of positively correlating with 


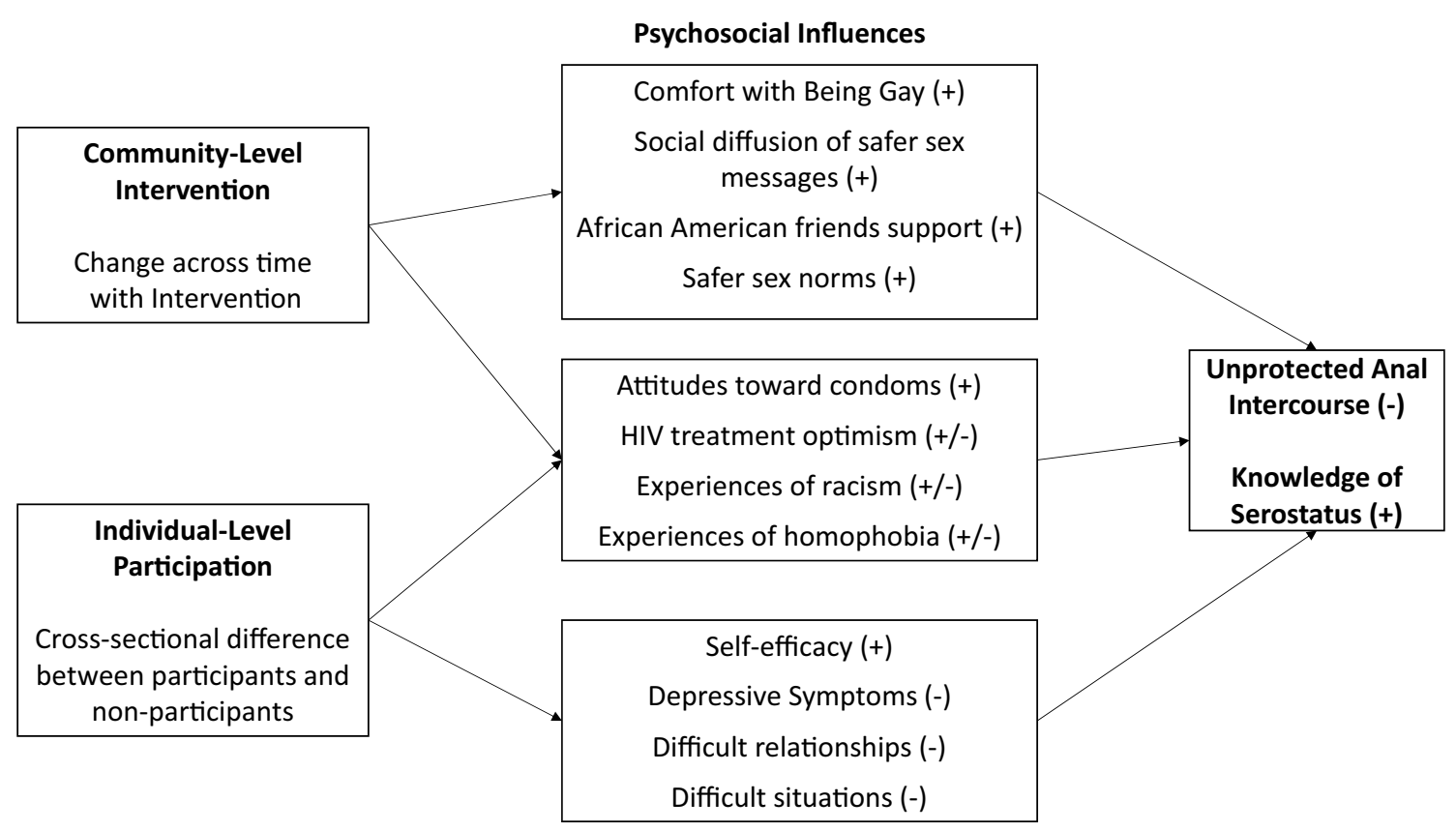

Fig. 1 Potential mechanisms of change through psychosocial influences in a community-level intervention; we hypothesized that some factors may be more amenable to intervention effects at the community level or at the individual level as shown

HIV behavioral risk reduction and increased knowledge of serostatus.

\section{Methods and Procedures}

\section{The Intervention}

The intervention was adapted for YBMSM from the original Mpowerment project [40], a community-level strategy aimed at mobilizing YMSM to develop sense of community, building social networks, and empowering them with the skills, motivation and resources to withstand negative environmental stressors such as stigma and discrimination in order to reduce risk for HIV. Based on empowerment theory [43], the intervention emphasized sex-positive affirmation of all orientations, enriching and strengthening YBMSM's pride in having same sex attraction, as well as nurturing and celebrating their sexuality. The model is also based on Diffusion of Innovations principles promoting active participation and peer influence, and engaging YBMSM as change agents for their peers $[44,45]$. These core principles of the intervention model were achieved through formal and informal outreach, small group discussions (M-Groups), publicity campaigns, social events, provision of safe project space; and facilitated by core groups and volunteers [40]. In addition to promoting safer sex behaviors and HIV testing, the intervention aimed to address psychosocial problems associated with HIV risktaking among YBMSM [19-21].
Adaptation entailed customizing the intervention content and strategies to be particularly sensitive to the cultural and social factors that potentially drive HIV risk among black MSM, including the experiences of social oppression and of being a racial/ethnic minority $[36,46]$. Thus, the intervention content and activities were designed and implemented with significant input from YBMSM project coordinators and a "Core Group" of other YBMSM, with assistance from a Community Advisory Board.

\section{Study Design}

The controlled trial was conducted in two communities, Dallas and Houston, Texas, which were carefully matched based on criteria that included size and having limited YBMSMfocused community-based organizations and programs. Serial cross-sectional surveys of YBMSM were conducted before and after the intervention in each community, at an interval of 1 year. Approximately 330 respondents were surveyed each year for 4 years (2009 to 2012) in each of two sites.

The study was originally designed with Dallas as the intervention community; Houston was to serve as the comparison community, and was not intended to receive intervention activities. However, a community-based organization in Houston obtained funding and began to deliver an Mpowerment intervention with overlapping content, though not as customized, to a similar population in the 4th year of the study, thus unintentionally creating a delayed 
intervention site. Intervention in the original site (Dallas) began before data collection wave 2 and continued through wave 4; intervention in the delayed site (Houston) began prior to and continued through wave 4 . We address this issue in analytical methods described below.

\section{Recruitment and Eligibility}

YBMSM were recruited using a modified time location sampling (TLS) strategy that was modeled after the National HIV Behavioral Surveillance Survey (NHBS) protocol [47] and adapted based on pilot work that established the feasibility for use in recruiting YBMSM in these specific communities. Participants were screened for eligibility using several criteria, including being black/African American; in the age range 18-29; been identified as male at birth; lived in the study community where they were surveyed (Dallas or Houston) for at least the previous 12 months; had sex with another man or multiple men in the past 12 months; being able to understand, read and speak English; and have not previously completed this same survey during the data collection period.

To conduct the TLS, community mapping via ethnographic methods, including observation and community interviews, was conducted in both Dallas and Houston to identify eligible venues. Men were recruited at bars, clubs, retail businesses, cafes and restaurants, social and religious organizations, adult bookstores and bathhouses, high-traffic street locations, parks and at special events such as gay pride festivals. Venues were excluded if they provided health or social services or HIV/STI testing or prevention services, or because of safety, low YBMSM attendance, or disapproval by owners. Two modifications from the NHBS protocol were made: (1) due to cost considerations, venues were only retained as a sampling location if at least 8 YBMSM entered during a 2-h time point (this was not an inclusion criterion in NHBS), and (2) venues and associated day/time periods were then purposively (rather than randomly as in NHBS) selected to maximize representation and productivity, which was composed of time periods that attract sufficient numbers of men to create schedules of 4-h sampling events [36].

Once study interviewers were stationed at the sampling venue, young black men who entered a defined intercept area and appeared age eligible were consecutively approached and screened for eligibility. Recruitment was also achieved through self-referrals from YBMSM who saw recruitment materials in the community, and snowball referrals from other study participants. After completing a brief field screener, eligible men who agreed to participate completed self-administered anonymous surveys using small handheld computers. Participants were compensated $\$ 30$ for completing any portion of the assessment in a pre-arranged location where surveys were conducted in private. All study procedures were approved by the institutional review boards at the investigators' home institutions and the CDC.

\section{Psychosocial Outcome Measures}

A series of brief scales were used to measure psychosocial experiences. These measures were rated on Likert-type or other scales as follows:

Social diffusion of safer sex messages was measured using 8 items derived from previous research [40]. Items included responses to how many times in the past 2 months respondents and their African American male friends 'talked about the importance of having safe (safer) sex,' 'shared ideas about how to avoid unsafe sex,' 'encouraged each other to practice safe sex,' etc. Frequency of occurrence was coded as 0 (Never), 1 (1-3 times a month), 2 (1-2 times a week), 3 (3-6 times a week), and 4 (Every day), yielding a range of 0 to 32 with higher scores indicating higher frequency of social diffusion of HIV prevention messages (Cronbach alpha $=0.93$ ).

Comfort with being gay was assessed using 6 items from previous research [40], including 3 reverse scored items on internalized homophobia, for example how happy/how proud are you being gay or bisexual, how comfortable are you with your sexual attraction to other men, does having sex with other men make you dislike yourself, do you ever wish that you were attracted only to women. Fivepoint response scales (not at all, slightly, moderately, very, extremely) yielded a total score range of 6-30 with higher scores indicating greater comfort (Cronbach alpha $=0.84$ ).

African American friends social support was assessed using 5 items adapted from previous research [40] originally adapted from Procidano and Heller [48] and asked how much social support respondents received from their African American gay/bisexual male friends. Responses were on a 6-point scale ranging from "disagree strongly" to "agree strongly" and yielding a total score range of 6-30, with higher scores indicating higher social support. (Cronbach alpha $=0.86$ ).

Social norms about safer sex was assessed using 5 items from previous research [40]. Respondents were asked how many of their friends 'always use condoms when having anal sex with a new partner', 'think you should avoid unsafe sex', 'think you should always have safe sex', 'only engage in safe sex practices', and how important their friends 'think it is to use a condom when having anal sex with a new partner.' Five-point scales yielded a total score range of 5-25 with higher scores representing higher perception of safer sex norms (Cronbach alpha $=0.79$ ).

Self-efficacy for safer sex was assessed using 4 items adapted from previous research [40] and asked how difficult it is for respondents to stop an unsafe sexual act by a sexual partner, engage only in safe sex when turned on, and 
negotiate safe sex with partner. Responses ranged from "not difficult at all" to "extremely difficult" on a 5-point scale yielding a total score range of 4-20 with higher scores indicating greater self-efficacy (Cronbach alpha $=0.81$ ).

Negative attitudes toward condom use was measured using 3 items derived from previous research [40, 42] and included "condoms ruin the sexual mood," "it is difficult to have an orgasm with condoms," and "it is difficult to keep an erection with condoms." Responses were on 5-point scales yielding a total score range of 3-15 with higher scores indicating more negative attitudes (Cronbach alpha $=0.83$ ).

Difficult sexual situations was measured using 10 items adapted from Díaz's original work with the construct [49]. The items included, 'how often in the last 12 months respondents had sex in difficult situations such as having sex "in order to feel good," when "lonely and depressed," when "you or your sex partner was high on drugs," and where "bringing up condoms would spoil a romantic mood." Responses ranged from "never" to "very often" along a 5-point scale yielding a total score range of 10-50 with higher scores indicating higher frequency of having difficult sex situations. (Cronbach alpha $=0.90)$.

Difficult relationships was measured using 4 items derived from Díaz's original work [49] that included responses to how often in the last 12 months you: 'were in a sexual situation where you wanted to feel really close and connected to the person with whom you were having sex', 'have been in a sexual situation with someone you were afraid of losing', 'have been in a sexual situation with someone you really wanted to please', 'have been in a sexual situation with a person who asks you to trust him'. Responses were on 5-point scales yielding a total score range of 4-20 with higher scores indicating higher frequency of difficult relationship situations (Cronbach alpha $=0.78$ ).

Depressive symptoms was measured using 9 items derived from the CES-D Scale [50] that included responses to how often participants felt they could not shake off the blues even with help from family or friends, felt depressed, thought their life had been a failure, felt fearful, had restless sleep, felt lonely, had crying spells, felt sad. Responses were on 3-point scales (rarely/none, some/occasional, most/all of the time) yielding a total score range of 0-27 with higher scores indicating higher frequency of depressive symptoms $($ Cronbach alpha $=0.90)$.

HIV treatment optimism was assessed using 4 items adapted from a previously developed scale of optimismskepticism in the context of HIV treatments [51]. Items included participants' belief that the current AIDS treatments make it easier to relax about sex, HIV-positive persons who take HIV medications are less likely to infect their sex partners during unsafe sex, it is safe to have anal sex without a condom with an HIV-positive man who has an undetectable viral load, if someone is HIV-positive but is being treated for his HIV, safe sex isn't important. The 5-point response scales yielded a total score range of 4-20 with higher scores indicating higher optimism (Cronbach alpha $=0.79$ ).

Experiences of racism was assessed using 11 items adapted from a previous scale [49] that included questions such as how often in the past year respondents had perceived civil rights violations, witnessed racial prejudice or discrimination, heard about someone else's experiences of racial prejudice, had been observed or followed while in public places because of race/ethnicity, etc. The 5-point response scales yielded a total score range of 1-55 with higher scores indicating higher frequency (Cronbach alpha $=0.82$ ).

Experiences of external homophobia was assessed using 7 items adapted from previous scale [49] included questions on how often in the past year participants were made fun of or called names for being effeminate (girly) or for being attracted to other men, beaten up for being effeminate or for being attracted to other men, heard that gay people will be alone when they grow old, heard that homosexuals are sinners, felt attraction to other men hurt and embarrassed their family, had to pretend not be attracted to other men in order to be accepted, had been treated unfairly at their job for being effeminate or attracted to other men. The 5-point response scales yielded a total score range of 7-35 with higher scores indicating higher frequency (Cronbach alpha $=0.75$ ).

In addition to these outcome measures, one further constructed variable was used as a demographic characteristic: Socioeconomic disadvantage was scored from 0 to 7 with one point each for not having a high school diploma/ GED, not currently employed full-time, personal income below $\$ 20,000$, running out of money at least one of last 12 months, having borrowed money in the last 12 months, history of incarceration, and history of homelessness.

\section{Data Analyses}

The current analyses are based on four waves of data collected from 2009 to 2012 in each of two sites, Dallas (which received treatment before and during waves 2,3 , and 4) and Houston (which received treatment before and during wave 4). The sample size objective for each assessment was approximately 333 per site per year, to provide $80 \%$ power to detect a $30 \%$ decrease in odds for dichotomous measures at alpha $=0.05$, assuming intraclass correlation equals zero.

The original analysis plan called for an analysis of covariance where the change across time in the intervention community is contrasted against change in the control community, thus accounting for baseline differences and random fluctuations. As noted above, a community-based organization introduced a very similar intervention to YBMSM in Houston, the intended comparison community, before and during the $4^{\text {th }}$ wave of data collection. To address this 
unplanned intervention activity, we modified the approach and applied a stepped wedge analysis to model the intervention effect [52]. In this model, the interaction term that represents the intervention effect is modified to include not only one point per year of intervention ( 0 through 3 ) in the original intervention site (Dallas), but also one point per year of intervention in the original comparison site (Houston), which received the intervention only in the final year. Thus the intervention effect variable is coded $0,1,2,3$ for the 4 years in Dallas, and 0, 0, 0, 1 for Houston. General linear regression models were used to determine intervention effect. We examined change in psychosocial and cognitive outcomes across time in the intervention condition compared to the control condition including modification (described above) for the introduction of the intervention in the delayed treatment site. The magnitude of these intervention effects is expressed in terms of units of each scale score per year.

We also estimated participation effects for each outcome, examining differences in the original intervention site between respondents who reported participation in the intervention activities described above versus those who did not. In these models, Dallas respondents who report having participated in M-groups, the core group, or volunteer activities are coded as one and others as zero for participation. For each of the psychosocial and cognitive variables examined for intervention effects, the difference between YBMSM in Dallas who reported participating in these intervention activities and those who did not then represents the comparison. These models of participation effects control for wave as a categorical variable and include only Dallas respondents during the three waves when the intervention was being conducted. We did not have analogous data from Houston to estimate participation effects during the intervention (in the final wave).

Finally, Spearman correlations were measured between each of the psychosocial and cognitive variables and two important behavioral outcomes: unprotected (condomless) receptive anal intercourse (URAI) with non-main partners, and knowledge of serostatus. For this analysis, URAI was dichotomized as any condomless receptive anal sex with non-main partners versus none. Knowledge of serostatus was defined by self-report as either being aware of one's HIV-positive status, or having tested HIV-negative in the past 6 months. The intervention was hypothesized to influence HIV risk through numerous routes, including by way of the community-level intervention effect and the individual-level participation effect on these and other (unmeasured or inconsistently measured, e.g., only in certain waves) psychosocial variables.

We predicted that some factors, including comfort with being gay, social diffusion of safer sex messages and safer sex norms would be more amenable to intervention effects at the community level across time, while others, including self-efficacy, depressive symptoms, difficult sexual situations and relationships, based on cross-sectional analysis, are more likely to change at the individual level, or both (Fig. 1). This prediction was informed by theories of behavior change and social influence (e.g. Theory of Reasoned Action, Health Belief Model [41, 42] and Diffusion of Innovation [44, 45]) as well as the literature on underlying determinants of HIV risk among black MSM [53].

\section{Results}

\section{Characteristics of the Sample}

Baseline demographic characteristics were similar between the Dallas and Houston samples (Table 1). Age was the only variable that differed between the two sites: a slightly larger proportion in Houston were 25 or older, while a slightly larger proportion in Dallas were under age 21. Overall, $97 \%$ identified as male and 3\% were male-to-female transgender women. Black/African-American race was an eligibility criterion, and 6\% also identified as Hispanic. Almost two-thirds were high school graduates or had a GED, and another $20 \%$ had at least some college, or associate or technical degree. Three-quarters identified as gay or homosexual, $24 \%$ as bisexual and only $1 \%$ as heterosexual. Eight percent reported having tested positive for HIV. On a seven-point checklist of socioeconomic disadvantages, $30 \%$ reported 0 or 1 items, $36 \%$ reported 2 or 3 , and $34 \%$ reported 4 or more items.

There were also no significant differences between the two cities at baseline in terms of sexual risk. The vast majority reported no anal sex without condoms during the past 2 months; only $14 \%$ to $19 \%$ reported any anal sex without condoms in each of 4 categories (insertive and receptive with boyfriend and casual partners). Less than $3 \%$ reported having 3 or more casual partners for insertive sex without condoms $(\mathrm{N}=25)$ or receptive sex without condoms $(\mathrm{N}=15)$, and less than $1 \%$ reported 5 or more $(\mathrm{N}=7$ and $\mathrm{N}=8$ respectively, data not shown).

\section{Intervention Effects (Community-Level)}

The intervention effect (Table 2) was statistically significant for two of the outcomes: social diffusion of safer sex messages $(\mathrm{z}(2477)=2.92, p=0.004)$ and comfort with being gay $(\mathrm{z}(2477)=2.45, p=0.01)$. Both changes were in the favorable direction, i.e., a net increase during the intervention when contrasted against change in the control condition. The mean value for the scale score of social diffusion of safer sex messages increased from 10.9 to 11.8 in the original intervention site (Fig. 2). In the delayed intervention site, the mean decreased from 12.8 to 11.5 during the 3 control years, and then further decreased to 10.9 in the fourth wave after the intervention was introduced. The mean value for comfort 
Table 1 Demographic characteristics of baseline survey of young African American MSM, Dallas and Houston Texas, 2009

\begin{tabular}{|c|c|c|c|}
\hline & $\begin{array}{l}\text { Combined n } \\
(\%) \mathrm{N}=666\end{array}$ & $\begin{array}{l}\text { Dallas } \\
\mathrm{n}(\%) \\
\mathrm{N}=337\end{array}$ & $\begin{array}{l}\text { Houston } \\
\mathrm{n}(\%) \\
\mathrm{N}=329\end{array}$ \\
\hline \multicolumn{4}{|l|}{$\operatorname{Age}^{\mathrm{a}}(\mathrm{p}=0.045)$} \\
\hline $18-20$ & $199(30)$ & $110(33)$ & $89(27)$ \\
\hline $21-24$ & $294(44)$ & $153(45)$ & $141(43)$ \\
\hline $25-29$ & $173(26)$ & $74(22)$ & $99(30)$ \\
\hline \multicolumn{4}{|l|}{ Gender (ns) } \\
\hline Male & $647(97)$ & $328(97)$ & $319(97)$ \\
\hline Transgender female & $19(3)$ & $9(3)$ & $10(3)$ \\
\hline \multicolumn{4}{|l|}{ Ethnicity (ns) } \\
\hline Hispanic & $41(6)$ & $21(6)$ & $20(6)$ \\
\hline \multicolumn{4}{|l|}{ Education (ns) } \\
\hline Less than high school & $109(16)$ & $58(17)$ & $51(16)$ \\
\hline High school/GED & $421(64)$ & $219(65)$ & $202(62)$ \\
\hline Some college or higher & $131(20)$ & $60(18)$ & $71(22)$ \\
\hline Missing & 5 & 0 & 5 \\
\hline \multicolumn{4}{|l|}{ Sexual orientation (ns) } \\
\hline Homosexual & $499(75)$ & $243(72)$ & $256(78)$ \\
\hline Bisexual & $161(24)$ & $91(27)$ & $70(21)$ \\
\hline Heterosexual & $4(1)$ & $2(1)$ & $2(1)$ \\
\hline Other/not sure & 2 & 1 & 1 \\
\hline \multicolumn{4}{|l|}{ HIV status (ns) } \\
\hline Positive & $50(8)$ & $19(6)$ & $31(9)$ \\
\hline \multicolumn{4}{|c|}{ Socioeconomic disadvantage (ns) } \\
\hline $0-1$ items & $195(30)$ & $94(28)$ & $101(32)$ \\
\hline $2-3$ items & $235(36)$ & $117(35)$ & $118(38)$ \\
\hline $4-5$ items & $181(28)$ & $106(31)$ & $75(24)$ \\
\hline $6-7$ items & $39(6)$ & $20(6)$ & $19(6)$ \\
\hline Missing & & 0 & 16 \\
\hline \multicolumn{4}{|c|}{ Sexual activity without condom } \\
\hline Insertive with boyfriend & $127(19)$ & $58(17)$ & $69(22)$ \\
\hline Receptive with boyfriend & $110(17)$ & $56(17)$ & $54(17)$ \\
\hline $\begin{array}{l}\text { Insertive with casual part- } \\
\text { ners }\end{array}$ & $111(17)$ & $50(15)$ & $61(19)$ \\
\hline $\begin{array}{l}\text { Receptive with casual } \\
\text { partners }\end{array}$ & $90(14)$ & $40(12)$ & $50(16)$ \\
\hline
\end{tabular}

Missing, not sure, and other values excluded from analyses

${ }^{\mathrm{a}} \chi^{2}(2 \mathrm{df})=6.22, p=0.045$

with being gay increased from 22.0 to 22.6 in the original intervention site. In the delayed intervention site, the mean decreased from 21.9 to 21.1 during the 3 control years, and then increased to 21.6 after the intervention was introduced.

\section{Participation (Exposure) Effects (Individual-Level)}

Participation in focused intervention activities (M-groups, core groups, and volunteer activities) increased steadily in Dallas across the three implementation waves, from $22 \%$
$(71 / 328)$ in wave 2 , to $26 \%(88 / 338)$ in wave 3 , to $31 \%$ (101/330) in wave 4 . The participation effect on psychosocial variables is only measured among Dallas respondents, as the difference in each outcome variable between those who report participating in intervention activities and those who do not. Participation effects were statistically significant for six outcomes (Table 2). Two differences were in the favorable direction: Intervention participants reported experiencing more social diffusion of safer sex messages (scale score of 12.4 vs. $11.1, \mathrm{~F}(1,926)=6.58, p=0.01)$, and fewer depressive symptoms $(3.9$ vs. $4.7, \mathrm{~F}(1,947)=4.54, p=0.03)$ than non-participants. However participation effects on two other outcomes were in the unfavorable direction: more negative attitudes toward condom use $(6.1$ vs. $5.4, \mathrm{~F}(1,948)=9.59$, $p=0.002)$ and more difficult situations regarding sexual decision-making (18.9 vs. $17.4, \mathrm{~F}(1,948)=7.07, p=0.008)$. Finally, participation effects were evident on two other variables for which there was no a priori favored direction: greater treatment optimism $(7.5$ vs. $6.8, \mathrm{~F}(1,948)=8.77$, $p=0.003)$, and more experiences of external homophobia $(17.0$ vs. $16.0, \mathrm{~F}(1,948)=4.56, p=0.03)$.

\section{Correlations Between Psychosocial Variables and Behavioral Outcomes}

Spearman correlations with URAI with non-main partners were significant $(p<0.01)$ for all variables except social diffusion of safer sex messages (Table 2). Because the desired outcome was a decrease in unprotected sex, the association was in the desirable direction in all cases, that is, negative correlations with the socially favorable variables (e.g., comfort with being gay) and positive correlations with the socially unfavorable variables (e.g., depression, negative attitudes toward condoms). Correlations with the three a priori neutral variables (e.g., treatment optimism) were all positive, meaning an undesirable association with more unprotected sex. These correlations are similar to those found in a baseline analysis from this same study [36]. Similarly, most correlations with knowledge of serostatus were significant $(p<0.01)$ and in the expected direction; however most of these correlations are smaller than correlations with unprotected sex.

\section{Summary of Significant Intervention and Participation Effects}

The left and center columns of Fig. 3 illustrate all psychosocial and cognitive variables for which there was a significant intervention or participation effect. As previously observed in Table 2, the two significant intervention effects were both favorable (increased comfort with being gay and social diffusion). Among the six significant participation effects, two were in the favorable direction: participants reported 
Table 2 Intervention effects and participation effects (unstandardized GLM coefficients as described in text), and correlation with unprotected (condomless) receptive anal intercourse (URAI) with non-main partners, 2009-2012

\begin{tabular}{|c|c|c|c|c|c|c|}
\hline Psychosocial variable & Range & Desired change & Intervention effect (SE) & Participation effect (SE) & $\begin{array}{l}\text { Correlation } \\
\text { with URAI }\end{array}$ & $\begin{array}{l}\text { Correlation with } \\
\text { knowledge of } \\
\text { serostatus }\end{array}$ \\
\hline $\begin{array}{l}\text { Social diffusion of safer sex } \\
\text { messages }\end{array}$ & $0-32$ & Increase & $0.96(0.33)^{* *}$ & $1.34(0.52)^{*}$ & 0.00 & $0.12 * * *$ \\
\hline Comfort with being gay & $6-30$ & Increase & $0.55(0.22)^{*}$ & $0.21(0.42)$ & $-0.10 * * *$ & $0.09 * * *$ \\
\hline Afr Am friends support & $6-30$ & Increase & $0.24(0.22)$ & $-0.13(0.38)$ & $-0.08 * * *$ & $0.07 * *$ \\
\hline Safer sex norm & $5-25$ & Increase & $0.10(0.15)$ & $-0.10(0.24)$ & $-0.14 * * *$ & $0.06 * *$ \\
\hline Self-efficacy for safer sex & $4-20$ & Increase & $-0.26(0.17)$ & $-0.48(0.28)$ & $-0.19 * * *$ & $0.08 * * *$ \\
\hline $\begin{array}{l}\text { Negative attitudes toward } \\
\text { condom use }\end{array}$ & $3-15$ & Reduce & $-0.03(0.14)$ & $0.68(0.22)^{* *}$ & $0.17 * * *$ & $-0.07 * *$ \\
\hline Depressive symptoms & $0-21$ & Reduce & $0.15(0.22)$ & $-0.73(0.34)^{*}$ & $0.12 * * *$ & $-0.06 * *$ \\
\hline Difficult situations & $10-50$ & Reduce & $0.23(0.36)$ & $1.51(0.57)^{* *}$ & $0.21 * * *$ & $-0.04 *$ \\
\hline Difficult relationships & $4-20$ & Reduce & $0.09(0.18)$ & $0.18(0.30)$ & $0.11 * * *$ & $-0.04 *$ \\
\hline HIV treatment optimism & $4-16$ & Neutral & $0.10(0.15)$ & $0.66(0.22)^{* *}$ & $0.11 * * *$ & -0.01 \\
\hline Experiences of racism & $11-55$ & Neutral & $0.44(0.43)$ & $0.05(0.70)$ & $0.09 * * *$ & $-0.04 *$ \\
\hline $\begin{array}{l}\text { Experiences of external homo- } \\
\text { phobia }\end{array}$ & $7-35$ & Neutral & $0.25(0.28)$ & $0.95(0.44)^{*}$ & $0.11 * * *$ & $-0.05 * *$ \\
\hline
\end{tabular}

$S E$ standard error

$* \mathrm{p}<0.05 * * \mathrm{p}<0.01 * * * \mathrm{p}<0.0001$ Significance tests for Intervention effects are based on z-statistics from regression models; significance tests for Participation effects are based on F-statistics from ANOVA; significance tests for correlations are based on Spearman rho

receiving more social diffusion of safer sex messages and experiencing fewer depressive symptoms. Two participation effects (on difficult situations and on negative condom attitudes) were in the unfavorable direction (both representing higher values on negative factors). Greater values were observed among participants than non-participants in both of the other two factors (HIV treatment optimism and experiences of homophobia), for which there was no a priori predicted direction of difference.

Finally for those psychosocial variables for which significant intervention or participation effects were observed, the middle and right columns of Fig. 3 show the two strongest correlations (from Table 2) with knowledge of serostatus (comfort with being gay, and social diffusion) and URAI (difficult situations and negative condom attitudes).

\section{Discussion}

As was expected, the results show a favorable communitylevel intervention effect on social diffusion of safer sex messages and on YBMSM comfort with being gay. At the individual level, participants responded more favorably than non-participants on social diffusion and depressive symptoms, but less favorably on attitudes toward condom use as well as the frequency of sex in difficult situations. Intervention participants also reported greater treatment optimism and more experiences of external homophobia, for which we had no a priori preferred direction.

The significant favorable finding on social diffusion demonstrates some validity for the conceptualization of this key component of the Mpowerment model [40]. The improvement in young men's comfort with being gay is a desirable outcome as it indicates improvement in positive sense of self, including self-acceptance, self-esteem, self-confidence and self-efficacy [54-56]. Several studies have shown that positive sense of self has positive influence on safer sex practices [57, 58], and mental health [59] among MSM. In contrast, negative perception of self, including internalized homophobia, also known as sexual self-stigma [60], has been associated with poor stress-coping strategies and can lead to depression, mental health problems, and increased risk behaviors such as substance abuse and unsafe sex [20, $21,55,56,61,62]$. Internalized homophobia can also be a barrier to getting tested for HIV and adhering to treatment as prevention [62]. It is important however, to recognize the possibility that embracing gay identity and networks may be associated with increased risk-taking [63, 64], an unintended consequence that must consistently be attended to when developing and implementing prevention interventions.

Depressive symptoms among YMSM may have multifaceted etiology including underlying psychological and psychiatric problems (e.g., preexisting depression, anxiety or substance abuse) [65]. However, results of population-based mental health studies have revealed evidence for higher rates 

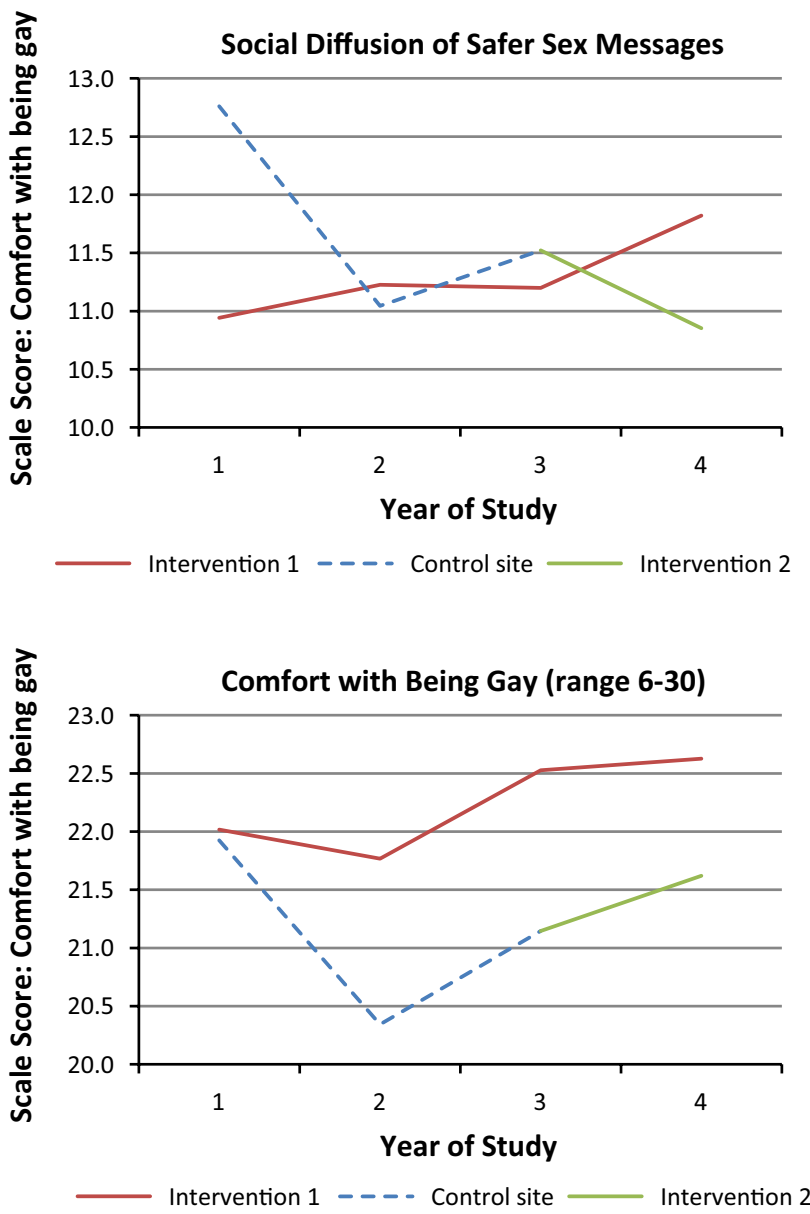

Fig. 2 Intervention effect measured as change across time in Social Diffusion of Safer Sex Messages and in Comfort with Being Gay during a community-level intervention for HIV risk reduction among young black men who have sex with men, 2009-2012

of depression, anxiety and other mental health disorders (panic, eating disorders, substance-use disorders, and suicidality) in individuals disclosing same-sex orientation or identifying as gay [13, 66, 67]. Furthermore, the lower frequency of depressive symptoms may be attributable to exposure to a home-like, safe, gay-positive atmosphere as part of the intervention, as well as participation in social events and activities aimed at fostering and strengthening participants' identity, social connections and support. These activities have a potential for improving participants' self-esteem and empowerment, and thus decreasing stress [68]. On the other hand, because people with more depressive symptoms may be less likely to attend social events, the direction of causality, if any, is not clear in this type of cross-sectional analysis. Either way, depressive symptoms and other mental health problems not only drive risk behavior $[54,69]$, but may also limit HIV medication adherence and viral load suppression among HIV-positive YBMSM [70]. Thus, intervention models that include screening and reduction of depression and other mental health symptoms can be beneficial for HIV prevention with YBMSM.

Suprisingly despite the favorable intervention and/or participation effects on comfort with being gay, social diffusion of safer sex and experience of depressive symptoms, there were unfavorable participation effects (greater values) on negative condom use attitudes and experiences of difficult sexual situations among intervention participants than non-participants. We can only speculate why the differences were in the desired direction for some outcomes and not for others. Greater (unfavorable) values on negative condom use attitudes and experiences of challenging sexual situations among participants could derive from a host of factors including well-documented obstacles such as relationship status, poor interpersonal communication, perception of risk and social environmental conditions [71] that may not have been sufficiently amenable to this intervention. Many YBMSM experience social, economic and cultural obstacles including unemployment, homelessness, incarceration history, family instability, breakup of relationships that may limit their self-agency and access to resources needed to navigate condom use and difficult sexual situations [36]. It is also possible that participating in social events, which was a major component of the intervention, may have inadvertently exposed participants to social and sexual networks that led to challenging sexual situations and relationships.

The findings also show greater treatment optimism among participants compared to non-participants, and more experiences of external homophobia. Greater treatment optimism may be a reflection of the new challenges to HIV prevention that have arisen since the availability of antiretroviral therapy (ART) that is associated with improvements in control of viral load and survival [72]. Although it is desirable that YBMSM have a positive disposition towards knowing their HIV status by getting tested, and adhering to treatment if positive, there is considerable evidence that high optimism and favorable feelings or beliefs about HIV treatment outcomes (e.g., beliefs regarding less severity of AIDS, reduced risks of HIV transmission, and less need to use condoms) can lead to increased risk behavior particularly among HIV-positive MSM [73, 74]. Data from behavioral surveys including longitudinal data have shown an association between treatment optimism and HIV acquisition and transmission risk behaviors in both white and black MSM $[73,75]$. Thus, these findings highlight the need to continue development and implementation of behavioral risk-reduction strategies in addition to promoting treatment as prevention. Providers must be encouraged to offer counseling and education, and reinforce the need to continue to use condoms, particularly with serodiscordant partners, and to recommend PrEP for HIV-negative YBMSM who have the most partners for condomless sex [76]. 


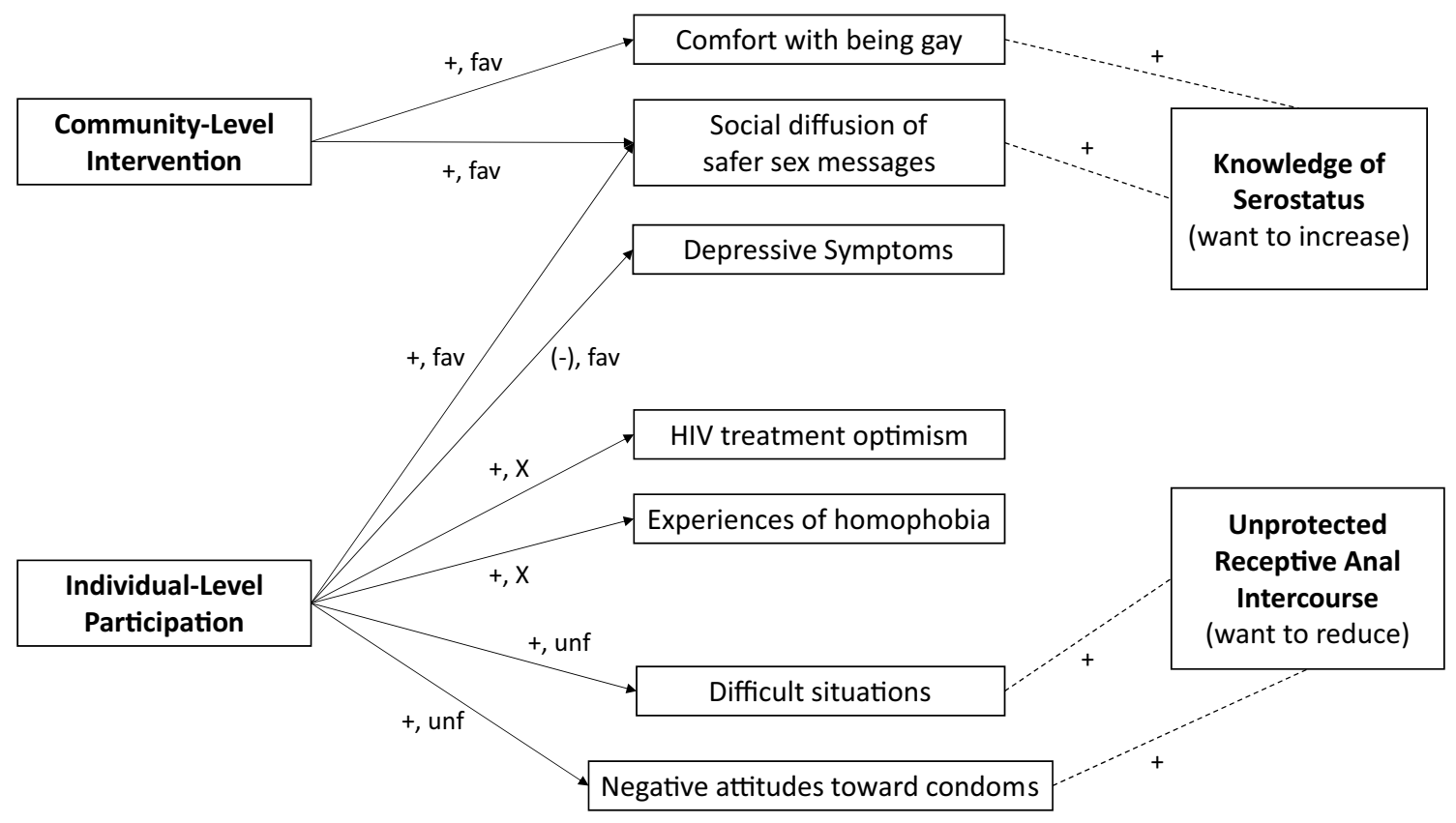

Fig. 3 Observed community-level and individual-level effects on psychosocial variables in a community-level intervention for young black MSM; Dallas and Houston, Texas, 2009-2012. Arrows on the left represent all significant intervention and participation effects on the psychosocial variables from Table 2. Community-level intervention effects represent differential change across time. Individual-level participation effects represent cross-sectional differences between participants and non-participants. A plus sign $(+)$ indicates increased or greater observed values, and a minus sign (-) indicates decreased or smaller observed values. Each of the observed changes or differences is then characterized as favorable (fav, shown at the top of the center column), unfavorable (unf, bottom of center column), or no a priori

The greater reported experiences of external homophobia among participants may be due to heightened awareness of this problem due to increased sensitization from intervention participation. While we did not posit a priori a direction of expected change, this finding underscores the need for interventions that empower and increase the resiliency and capacity of YBMSM to withstand perceived and experienced discrimination.

Correlations among outcomes may also affect the pattern of results. For example, if a participant has sex "in order to feel good," depression could either increase or decrease as a result. Psychosocial variables such as those described here are intercorrelated and may work together to make HIV prevention more difficult in vulnerable populations [17, 18, 21].

As shown in Table 2, eleven of the twelve psychosocial and cognitive variables correlated significantly with unprotected sex, and eleven of the twelve correlated significantly with knowledge of serostatus, although most of the correlations were small. As expected, variables for which the desired direction of change was an increase (e.g., selfefficacy and safer sex norms) were empirically associated preferred direction (X, middle of center column). Among those variables for which significant intervention or participation effects were observed, the two variables most strongly correlated with knowledge of serostatus and the two most strongly correlated with unprotected receptive anal intercourse with non-main partners are shown as examples (four dotted lines on the right). All four correlations shown are numerically positive, meaning that greater values on the psychosocial variable (middle column) were associated with greater likelihood of knowledge of serostatus (which is the favorable direction), or greater likelihood of unprotected receptive sex with non-main partners (which is the unfavorable direction)

with less unprotected sex and greater knowledge of serostatus. Those for which a reduction was desired (e.g., difficult situations and negative condom attitudes) were associated with more unprotected sex and less knowledge of serostatus. These results are consistent with long-standing theories of behavior change [41, 42, 45]. Greater values on the three variables for which there was no a priori direction (treatment optimism, and perception of racism and external homophobia) were mostly associated with behavioral changes in the unfavorable direction: more unprotected sex and less knowledge of serostatus.

Finally, Fig. 3 illustrates how potential intervention effects on behavioral outcomes such as safer sex and getting tested for HIV may be channeled through favorable changes in intermediate psychosocial influences including comfort with being gay and receipt of safer sex messages. Potential unfavorable behavioral outcomes such as unprotected sex may also be influenced by unfavorable psychosocial outcomes, including negative attitudes toward condoms and finding oneself in difficult sexual situations. These pathways 
of behavioral change are consistent with established behavior change theories.

The findings reported here have a number of limitations that may pose a confounding bias in the findings of the study. First, the two-community design limits the ability to determine accurately the effects of the intervention [77]. With only a single pair of communities the study was vulnerable to random fluctuations, a likely explanation for the large baseline differences observed in Fig. 2. With a larger number of communities we would expect to see smaller fluctuations across time. Other plausible explanations include use of serial cross-sectional data that reflect the events of a specific point in time and may not have been the most efficient in capturing the actual trend of change in these outcomes. An additional potential explanation is the recruitment options whereby study participants were recruited from locations and venues that sometimes closed or relocated between waves of data collection leading to inconsistent pool of survey respondents, a limitation further exacerbated by the limited number of communities. Given these constraints, in addition to limited financial resources for a more robust study design, and the early introduction of the intervention in the control community, this was the best methodological option available under the circumstance.

Second, the participation effects are analyzed with individuals as the unit of exposure, which is highly subject to self-selection bias. Because motivated residents are more likely to participate than non-motivated residents, we cannot say with certainty whether participation yielded improvements in psychosocial variables, or whether individuals with healthier psychosocial profiles were simply more likely to participate in the intervention. Likewise, the Spearman correlation findings do not represent causal relationships between psychosocial variables, knowledge of serostatus, and unprotected anal sex. However, while the ultimate goal of HIV interventions is to reduce risk of transmission, these findings highlight the potential benefits of targeting interventions on the broader health issues of YBMSM, including cooccurring psychosocial problems, e.g., reducing depressive symptoms that can result from stigmatization and homophobia, and promoting positive self-identity of YBMSM to enhance treatment adherence and risk reduction. We acknowledge that although the Mpowerment model can be adapted to address behaviors around testing, PrEP, and the HIV continuum of care, the effort to reach a large proportion of the population is expensive; a focus on recruiting the highest-risk individuals for M-groups and other intervention activities might improve cost-effectiveness.

As the HIV prevention climate shifts from condom promotion to HIV testing, PrEP and ART, addressing psychosocial factors and environmental determinants of these outcomes, such as depression, social isolation and low sense of self and agency that result from stigma, racism and homophobia should remain a critical focus of interventions and programs to positively influence not only individual risk behaviors, but also broader health concerns of YBMSM. Such an approach offers a likelilhood of sustainable desired outcomes in HIV prevention.

Acknowledgements This work was supported by the Centers for Disease Control and Prevention (CDC) cooperative agreement No. UR6PS000334. Susan Kegeles was the principal investigator. We thank all the participants, field staff, and the entire study team for their dedication to the study. We also want thank Mary Mullins of CDC's division of HIV and AIDS prevention (DHAP) for lending her expertise in EndNote reference management, and Dr. Yamir Salabarría-Peña of the same division for abstract translation support.

Disclaimer The findings and conclusions in this report are those of the authors and do not necessarily represent the official position of the Centers for Disease Control and Prevention.

\section{Compliance with Ethical Standards}

Conflict of interest Authors declare that they have no conflict of interests and no financial disclosures.

Informed Consent Informed consent was obtained from all individual participants included in the study.

Research Involving Human Participants and/or Animals All procedures performed in studies involving human participants were in accordance with the ethical standards of the institutional and/or national research committee and with the 1964 Helsinki declaration and its later amendments or comparable ethical standards. This study was approved by institutional review boards of participating authors' institutions.

\section{References}

1. Cohen MS, Chen YQ, McCauley M, et al. Antiretroviral therapy for the prevention of HIV-1 transmission. N Engl J Med. 2016;375(9):830-9.

2. Grant RM, Lama JR, Anderson PL, et al. Preexposure chemoprophylaxis for HIV prevention in men who have sex with men. N Engl J Med. 2010;363(27):2587-99.

3. Heffelfinger JD, Owen SM, Hendry RM, Lansky A. HIV testing: the cornerstone of HIV prevention efforts in the USA. Future Virol. 2011;6(11):1299-317.

4. Centers for Disease Control and Prevention. Compendium of evidience-based intervention and best practices for HIV prevention, risk reduction chapter. https://www.cdc.gov/hiv/research/inter ventionresearch/compendium/rr/index.html. 2017. Accessed 19 July 2017.

5. Centers for Disease Control and Prevention. HIV Surveillance: Men who have sex with men (MSM) through 2015. https://www. cdc.gov/hiv/ppt/library/slidesets/cdc-hiv-surveillance-slides-msm. pptx. 2015. Accessed 19 July 2017.

6. Hightow-Weidman L, LeGrand S, Choi SK, Egger J, Hurt CB, Muessig KE. Exploring the HIV continuum of care among young black MSM. PLoS ONE. 2017;12(6):e0179688.

7. Millett GA, Peterson JL, Wolitski RJ, Stall R. Greater risk for HIV infection of black men who have sex with men: a critical literature review. Am J Public Health. 2006;96(6):1007-19. 
8. Zanoni BC, Mayer KH. The adolescent and young adult HIV cascade of care in the United States: exaggerated health disparities. AIDS Patient Care STDS. 2014;28(3):128-35.

9. Berg RC, Ross MW, Weatherburn P, Schmidt AJ. Structural and environmental factors are associated with internalised homonegativity in men who have sex with men: findings from the European MSM Internet Survey (EMIS) in 38 countries. Soc Sci Med. 2013;78:61-9.

10. Martikainen P, Bartley M, Lahelma E. Psychosocial determinants of health in social epidemiology. Int $\mathrm{J}$ Epidemiol. 2002;31(6):1091-3.

11. Levy ME, Wilton L, Phillips G 2nd, et al. Understanding structural barriers to accessing HIV testing and prevention services among black men who have sex with men (BMSM) in the United States. AIDS Behav. 2014;18(5):972-96.

12. Saleh LD, van den Berg JJ, Chambers CS, Operario D. Social support, psychological vulnerability, and HIV risk among African American men who have sex with men. Psychol Health. 2016;31(5):549-64.

13. Choi KH, Paul J, Ayala G, Boylan R, Gregorich SE. Experiences of discrimination and their impact on the mental health among African American, Asian and Pacific Islander, and Latino men who have sex with men. Am J Public Health. 2013;103(5):868-74.

14. Han CS, Ayala G, Paul JP, Boylan R, Gregorich SE, Choi KH. Stress and coping with racism and their role in sexual risk for HIV among African American, Asian/Pacific Islander, and Latino men who have sex with men. Arch Sex Behav. 2015;44(2):411-20.

15. Meyer IH. Prejudice, social stress, and mental health in lesbian, gay, and bisexual populations: conceptual issues and research evidence. Psychol Bull. 2003;129(5):674-97.

16. O'Leary A, Jemmott JB 3rd, Stevens R, Rutledge SE, Icard LD. Optimism and education buffer the effects of syndemic conditions on HIV status among African American men who have sex with men. AIDS Behav. 2014;18(11):2080-8.

17. Safren SA, Reisner SL, Herrick A, Mimiaga MJ, Stall RD. Mental health and HIV risk in men who have sex with men. J Acquir Immune Defic Syndr. 2010;55(Suppl 2):S74-7.

18. Dyer TP, Regan R, Pacek LR, Acheampong A, Khan MR. Psychosocial vulnerability and HIV-related sexual risk among men who have sex with men and women in the United States. Arch Sex Behav. 2015;44(2):429-41.

19. Jie W, Ciyong L, Xueqing D, Hui W, Lingyao H. A syndemic of psychosocial problems places the MSM (men who have sex with men) population at greater risk of HIV infection. PLoS ONE. 2012;7(3):e32312.

20. Mustanski B, Garofalo R, Herrick A, Donenberg G. Psychosocial health problems increase risk for HIV among urban young men who have sex with men: preliminary evidence of a syndemic in need of attention. Ann Behav Med. 2007;34(1):37-45.

21. Stall R, Mills TC, Williamson J, et al. Association of co-occurring psychosocial health problems and increased vulnerability to HIV/ AIDS among urban men who have sex with men. Am J Public Health. 2003;93(6):939-42.

22. Bimbi DS, Nanin JE, Parsons JT, Vicioso KJ, Missildine W, Frost DM. Assessing gay and bisexual men's outcome expectancies for sexual risk under the influence of alcohol and drugs. Subst Use Misuse. 2006;41(5):643-52.

23. Halkitis PN. Discrimintation and homophobia fuel the HIV epidemic in gay and bisexaul men. Psychol AIDS Exch Newsl. 2012;1:4.

24. Logie CH, Newman PA, Chakrapani V, Shunmugam M. Adapting the minority stress model: associations between gender nonconformity stigma, HIV-related stigma and depression among men who have sex with men in South India. Soc Sci Med. 2012;74(8):1261-8.
25. Ploderl M, Tremblay P. Mental health of sexual minorities. A systematic review. Int Rev Psychiatry. 2015;27(5):367-85.

26. Dyer TP, Shoptaw S, Guadamuz TE, et al. Application of syndemic theory to black men who have sex with men in the Multicenter AIDS Cohort Study. J Urban Health. 2012;89(4):697-708.

27. Fields EL, Bogart LM, Galvan FH, Wagner GJ, Klein DJ, Schuster MA. Association of discrimination-related trauma with sexual risk among HIV-positive African American men who have sex with men. Am J Public Health. 2013;103(5):875-80.

28. Centers for Disease Control and Prevention. Social determinants of health and selected HIV care outcomes among adults with diagnosed HIV infection in 32 states and the District of Columbia, 2014. HIV AIDS Surveill Rep; 2016 21(No. 7). https://www.cdc. gov/hiv/pdf/library/reports/surveillance/cdc-hiv-surveillancesupplemental-report-vol-21-7.pdf. 2016. Accessed 31 July 2017.

29. Millett GA, Jeffries WL, Peterson JL, et al. Common roots: a contextual review of HIV epidemics in black men who have sex with men across the African diaspora. Lancet. 2012;380(9839):411-23.

30. Sutton MY, Gray SC, Elmore K, Gaul Z. Social determinants of HIV disparities in the southern united states and in counties with historically black colleges and universities (HBCUs), 2013-2014. PLoS ONE. 2017;12(1):e0170714.

31. Wang K, Pachankis JE. Gay-related rejection sensitivity as a risk factor for condomless sex. AIDS Behav. 2016;20(4):763-7.

32. Mattocks KM, Sullivan JC, Bertrand C, Kinney RL, Sherman MD, Gustason C. Perceived stigma, discrimination, and disclosure of sexual orientation among a sample of lesbian veterans receiving care in the department of veterans affairs. LGBT Health. 2015;2(2):147-53.

33. Dentato MP, Halkitis PN, Orwat J. Minority stress theory: an examination of factors surrounding sexual risk behavior among gay \& bisexual men who use club drugs. J Gay Lesbian Soc Serv. 2013;25(4):509-25.

34. Durso LE, Meyer IH. Patterns and predictors of disclosure of sexual orientation to healthcare providers among lesbians, gay men, and bisexuals. Sex Res Social Policy. 2013;10(1):35-42.

35. Hussen SA, Harper GW, Bauermeister JA, Hightow-Weidman LB. Psychosocial influences on engagement in care among HIVpositive young black gay/bisexual and other men who have sex with men. AIDS Patient Care STDS. 2015;29(2):77-85.

36. Huebner DM, Kegeles SM, Rebchook GM, et al. Social oppression, psychological vulnerability, and unprotected intercourse among young Black men who have sex with men. Health Psychol. 2014;33(12):1568-78.

37. Baumler E, Glassman J, Tortolero S, et al. Examination of the relationship between psychosocial mediators and intervention effects in it's your game: an effective HIV/STI/pregnancy prevention intervention for middle school students. AIDS Res Treat. 2012;2012:298494.

38. DiClemente RJ, Crittenden CP, Rose E, et al. Psychosocial predictors of HIV-associated sexual behaviors and the efficacy of prevention interventions in adolescents at-risk for HIV infection: what works and what doesn't work? Psychosom Med. 2008;70(5):598-605.

39. Lyles CM, Kay LS, Crepaz N, et al. Best-evidence interventions: findings from a systematic review of HIV behavioral interventions for US populations at high risk, 2000-2004. Am J Public Health. 2007;97(1):133-43.

40. Kegeles SM, Hays RB, Coates TJ. The Mpowerment Project: a community-level HIV prevention intervention for young gay men. Am J Public Health. 1996;86(8):1129-36.

41. Bandura A. Self-efficacy: toward a unifying theory of behavioral change. Psychol Rev. 1977;84(2):191-215.

42. Fishbein M, Ajzen I. Belief, attitude, intention, and behavior: an introduction to theory and research. Reading: Addison Wesley; 1980. 
43. Perkins DD, Zimmerman MA. Empowerment theory, research, and application. Am J Community Psychol. 1995;23(5):569-79.

44. Barker K. Diffusion of innovations: a world tour. J Health Commun. 2004;9(Suppl1):131-7.

45. Rogers EM. Diffision of innovations. New York: Free Press; 2003.

46. Parker CM, Garcia J, Philbin MM, Wilson PA, Parker RG, Hirsch JS. Social risk, stigma and space: key concepts for understanding HIV vulnerability among black men who have sex with men in New York City. Cult Health Sex. 2017;19(3):323-37.

47. Centers for Disease Control and Prevention. HIV testing among men who have sex with men-21 cities, United States, 2008. MMWR Morb Mortal Wkly Rep. 2011;60(21):694-9.

48. Procidano ME, Heller K. Measures of perceived social support from friends and from family: three validation studies. Am J Community Psychol. 1983;11(1):1-24.

49. Diaz RM, Ayala G, Bein E. Sexual risk as an outcome of social oppression: data from a probability sample of Latino gay men in three US cities. Cult Divers Ethnic Minor Psychol. 2004;10(3):255-67.

50. Radloff LS. The CES-D scale: a self-report depression scale for research in the general population. Appl Psychol Meas. 1977;1(3):385-401.

51. Van de Ven P, Crawford J, Kippax S, Knox S, Prestage G. A scale of optimism-scepticism in the context of HIV treatments. AIDS Care. 2000;12(2):171-6.

52. Hemming K, Lilford R, Girling AJ. Stepped-wedge cluster randomised controlled trials: a generic framework including parallel and multiple-level designs. Stat Med. 2015;34(2):181-96.

53. Mustanski BS, Newcomb ME, Du Bois SN, Garcia SC, Grov C. HIV in young men who have sex with men: a review of epidemiology, risk and protective factors, and interventions. J Sex Res. 2011;48(2-3):218-53

54. Klein H. Depression and HIV risk taking among men who have sex with other men (MSM) and who use the internet to find partners for unprotected sex. J Gay Lesbian Ment Health. 2014;18(2):164-89.

55. Preston DB, D'Augelli AR, Kassab CD, Starks MT. The relationship of stigma to the sexual risk behavior of rural men who have sex with men. AIDS Educ Prev. 2007;19(3):218-30.

56. Rosario M, Schrimshaw EW, Hunter J. A model of sexual risk behaviors among young gay and bisexual men: longitudinal associations of mental health, substance abuse, sexual abuse, and the coming-out process. AIDS Educ Prev. 2006;18(5):444-60.

57. Hart T, Peterson JL. Predictors of risky sexual behavior among young African American men who have sex with men. Am J Public Health. 2004;94(7):1122-4.

58. White D, Stephenson R. Identity formation, outness, and sexual risk among gay and bisexual men. Am J Mens Health. 2014;8(2):98-109.

59. Kertzner RM, Meyer IH, Frost DM, Stirratt MJ. Social and psychological well-being in lesbians, gay men, and bisexuals: the effects of race, gender, age, and sexual identity. Am J Orthopsychiatry. 2009;79(4):500-10.

60. Herek GM, Gillis JR, Cogan JC. Internalized stigma among sexual minority adults: insights from a social psychological perspective. Stigma Health. 2015;1:18-34.

61. Frost DM, Meyer IH. Internalized homophobia and relationship quality among lesbians, gay men, and bisexuals. J Couns Psychol. 2009;56(1):97-109.
62. Pyun T, Santos GM, Arreola S, et al. Internalized homophobia and reduced HIV testing among men who have sex with men in China. Asia Pac J Public Health. 2014;26(2):118-25.

63. Flores SA, Mansergh G, Marks G, Guzman R, Colfax G. Gay identity-related factors and sexual risk among men who have sex with men in San Francisco. AIDS Educ Prev. 2009;21(2):91-103.

64. Frankis JS, Flowers P. Public sexual cultures: a systematic review of qualitative research investigating men's sexual behaviors with men in public spaces. J Homosex. 2009;56(7):861-93.

65. AIDS Education Training Center (AETC). Major depression and other depressive disorders. https://www.aidsetc.org/guide/major -depression-and-other-depressive-disorders. 2014. Accessed 23 Aug 2017.

66. Hatzenbuehler ML, McLaughlin KA, Keyes KM, Hasin DS. The impact of institutional discrimination on psychiatric disorders in lesbian, gay, and bisexual populations: a prospective study. Am J Public Health. 2010;100(3):452-9.

67. King M, Semlyen J, Tai SS, et al. A systematic review of mental disorder, suicide, and deliberate self harm in lesbian, gay and bisexual people. BMC Psychiatry. 2008;8:70.

68. Crisp D, Griffiths K, Mackinnon A, Bennett K, Christensen H. An online intervention for reducing depressive symptoms: secondary benefits for self-esteem, empowerment and quality of life. Pyschiatry Res. 2014;216(1):60-6.

69. Chen YH, Raymond HF. Associations between depressive syndromes and HIV risk behaviors among San Francisco men who have sex with men. AIDS Care. 2017;29(12):1538-42.

70. Gonzalez JS, Batchelder AW, Psaros C, Safren SA. Depression and HIV/AIDS treatment nonadherence: a review and meta-analysis. J Acquir Immune Defic Syndr. 2011;58(2):181-7.

71. Ostergren JE, Rosser BR, Horvath KJ. Reasons for non-use of condoms among men who have sex with men: a comparison of receptive and insertive role in sex and online and offline meeting venue. Cult Health Sex. 2011;13(2):123-40.

72. Brennan DJ, Welles SL, Miner MH, Ross MW, Rosser BR. HIV treatment optimism and unsafe anal intercourse among HIVpositive men who have sex with men: findings from the positive connections study. AIDS Educ Prev. 2010;22(2):126-37.

73. Peterson JL, Miner MH, Brennan DJ, Rosser BR. HIV treatment optimism and sexual risk behaviors among HIV positive African American men who have sex with men. AIDS Educ Prev. 2012;24(2):91-101

74. Sullivan PS, Drake AJ, Sanchez TH. Prevalence of treatment optimism-related risk behavior and associated factors among men who have sex with men in 11 states, 2000-2001. AIDS Behav. 2007;11(1):123-9.

75. Levy ME, Phillips G 2nd, Magnus M, et al. A longitudinal analysis of treatment optimism and HIV acquisition and transmission risk behaviors among black men who have sex with men in HPTN 061. AIDS Behav. 2017;21(10):2958-72.

76. Johnson WD, O'Leary A, Flores SA. Per-partner condom effectiveness against HIV for men who have sex with men. AIDS. 2018;32(11):1499-505.

77. Koepsell TD. Epidemiologic issues in the design of community intervention trials. In: Brownson RC, Pettiti DB, editors. Applied epidemiolgy: theory to practice. New York: Oxford University Press; 1998.

Publisher's Note Springer Nature remains neutral with regard to jurisdictional claims in published maps and institutional affiliations. 


\section{Affiliations}

Agatha N. Eke ${ }^{1} \cdot$ Wayne D. Johnson $^{1} \cdot$ Ann O'Leary $^{1} \cdot$ Gregory M. Rebchook ${ }^{2}$ - David M. Huebner ${ }^{3}$. John L. Peterson ${ }^{4}$. Susan M. Kegeles ${ }^{2}$

1 Division of HIV/AIDS Prevention, National Center for HIV/ AIDS, Viral Hepatitis, STD, and TB Prevention, U.S.

Centers for Disease Control and Prevention, 1600 Clifton Rd MS-37, Atlanta, GA 30333, USA

2 University of California, San Francisco, San Francisco, CA, USA
3 George Washington University, Washington, DC, USA

4 Georgia State University, Atlanta, GA, USA 